\title{
Pore-scale investigation of residual oil displacement in surfactant- polymer flooding using nuclear magnetic resonance experiments
}

\author{
Zhe-Yu Liu $^{1} \cdot$ Yi-Qiang Li $^{1} \cdot$ Ming-Hui Cui ${ }^{1} \cdot$ Fu-Yong Wang $^{1} \cdot$ A. G. Prasiddhianti ${ }^{1}$
}

Received: 26 July 2014 / Published online: 6 January 2016

(c) The Author(s) 2015. This article is published with open access at Springerlink.com

\begin{abstract}
Research on the Gangxi III area in the Dagang Oilfield shows that there was still a significant amount of oil remaining in oil reservoirs after many years of polymer flooding. This is a potential target for enhanced oil recovery (EOR). Surfactant-polymer (SP) flooding is an effective chemical EOR method for mobilizing residual oil and improving displacement efficiency macroscopically, but the microscopic oil displacement efficiency in pores of different sizes is unclear. Nuclear magnetic resonance (NMR) is an efficient method for quantifying oil saturation in the rock matrix and analyzing pore structures. In this paper, the threshold values of different pore sizes were established from the relationship between mercury injection curves and NMR $T_{2}$ spectrums. The distribution and migration of residual oil in different flooding processes was evaluated by quantitatively analyzing the change of the relaxation time. The oil displaced from pores of different sizes after the water flood, polymer flood, and the SP flood was calculated, respectively. Experimental results indicate that (1) the residual oil in medium pores contributed the most to the incremental oil recovery for the SP flood, ranging from $40 \%$ to $49 \%$, and small pores usually contributed $<30 \%$; (2) the residual oil after the SP flood was mainly distributed in small and medium pores; the residual oil in medium pores accounted for $47.3 \%-54.7 \%$, while that trapped in small pores was $25.7 \%-42.5 \%$. The residual oil in small and medium pores was the main target for EOR after the SP flood in oilfields.
\end{abstract}

Yi-Qiang Li

lyq89731007@163.com

1 EOR Research Institute, China University of Petroleum, Beijing 102249, China

Edited by Yan-Hua Sun
Keywords Nuclear magnetic resonance (NMR) .

Surfactant-polymer (SP) flood · Residual oil distribution · Displacement mechanism · Core displacement test

\section{Introduction}

After over 30 years of water flooding and polymer flooding, the Dagang Oilfield is now a mature oil field with its water cut reaching the economic limit. However, as much as $70 \%$ of the original oil in place (OOIP) may remain in the reservoir after secondary recovery processes (Sorbie 1991). A large portion of the residual oil is capillary trapped (Lake 1989). To tackle the residual oil saturation and revitalize this reservoir, a tertiary recovery is required. Surfactant-polymer (SP) flooding has been proved to be an efficient tertiary method for most major oilfields in China. To apply SP flooding in the Dagang Oilfield and optimize the process in heterogeneous reservoirs, it is necessary to predict the residual oil after the SP flood and identify the displacement efficiency in pores of different sizes.

Several experimental/numerical techniques have been proposed to measure or predict the residual oil distribution after displacement processes. For example, a widely used traditional method is to measure residual oil through analysis of cast thin sections of a reservoir core (Zao et al. 2009). This method damages reservoir cores while obtaining slices. Furthermore, fractured cores, unconsolidated sands, and mud cannot be cut into slices using this method. Another experimental technique is to use a microvisualized model instead of a reservoir core to simulate a displacement process as well as the distribution of residual oil (Wang et al. 2010). However, this method does not take into account the influence of interstitial matter on the distribution of residual oil. X-ray computed tomography is 
often used to detect the rock matrix, but it is not sensitive to fluid changes (Vinegar 1986; de Argandona et al. 1999; Liu 2013). Numerical simulations require some assumptions in order to achieve mathematical completeness. In addition, reservoir parameters are uncertain and hard to determine. Therefore, there is usually a discrepancy between simulation results and actual conditions ( $\mathrm{Li}$ et al. 2006). Nuclear magnetic resonance (NMR) is a quick, accurate, non-destructive, and widely used technology for core testing (Kleinberg and Vinegar 1996; Xie and Xiao 2007; Zhao et al. 2011). In NMR measurements, the received signals originate only from fluids in pores. To differentiate hydrocarbons from brine, brine is doped with paramagnetic ions to shield the signals from water, so that the signals only come from the oil. NMR $T_{2}$ relaxation time represents the fluid content in the pores of different sizes. The longer $T_{2}$ relaxation time corresponds to the larger pores, and vice versa (Williams et al. 1991; Gleeson et al. 1993; Cowan 1997). The residual oil distributions in pores of different sizes are quantified through the $T_{2}$ distribution analysis, and the accurate oil saturation can be calculated to investigate the oil movement in pores of different sizes. In our study, the NMR technique was used to evaluate the residual oil distribution after water flooding, polymer flooding, and SP flooding to study the "kickoff" mechanism of the residual oil.

\section{NMR test principles}

NMR is commonly used to image oil and water distributions in reservoir rocks by analyzing the relaxation time of reservoir fluids in the petroleum industry. NMR test signals come from hydrogen atoms, so more hydrogen atoms lead to stronger signals (Wang et al. 2001; Liu et al. 2004). However, it is difficult to distinguish signals from water and oil phases due to the presence of hydrogen atoms in both water and hydrocarbons. In order to separate oil-phase signals from mixed signals, the core slugs are doped in a paramagnetic solution (Guo and $\mathrm{Gu}$ 2005). Paramagnetic ions are able to diffuse into the core samples to shield NMR $T_{2}$ signals from the water phase.

$\mathrm{Mn}^{2+}$ ions, as paramagnetic ions in experiments, are able to penetrate into the water phase but not the oil phase. As a result, NMR $T_{2}$ signals from the water phase reduce below the dead time of NMR, while the signals from oil remain detectable without any loss (Kleinberg and Vinegar 1996; Gong et al. 2006). At the same time, the nonionic surfactant was chosen to have a large optimum salinity window and low susceptibility to divalent cations. Therefore, the addition of $\mathrm{Mn}^{2+}$ ions in the surfactant would not significantly affect the interfacial tension. Because adding $\mathrm{Mn}^{2+}$ ions makes the branched chains of polymer molecules crinkle and decreases the viscosity of polymer solutions, different polymer concentrations were studied to avoid loss of mobility control at low polymer concentrations. The residual oil saturation in the core sample is closely related to NMR $T_{2}$ signals, and hence the change of the residual oil distribution after water flooding, polymer flooding, and SP flooding can be calculated and compared by analyzing NMR $T_{2}$ signals. The NMR $T_{2}$ relaxation distribution is an analytical method for analyzing the residual oil distribution. The relation between the NMR $T_{2}$ relaxation time and pore sizes is described by the following equation (Ausbrooks et al. 1999):

$\frac{1}{T_{2}}=\rho_{2} \frac{S}{V}$,

where $T_{2}$ is the NMR $T_{2}$ relaxation time, $\rho_{2}$ is the interfacial relaxivity determined by the mineral constituents and surficial properties of the pores, and $\frac{S}{V}$ is the specific pore surface area per volume which is inversely correlated with the pore diameter.

The total relaxation time is the sum of the relaxation time from the individual phases from different pore sizes: $S(t)=\Sigma A_{i} \exp \left(-t / T_{2 i}\right)$,

where $S(t)$ is a dimensionless parameter representing the total relaxation time; $A_{i}$ is the ratio of the phase of which relaxation time is $T_{2 i}$ to the total, or the ratio of the pores which is represented by $T_{2 i}$ to the total pore volume.

According to this method, the NMR spectrums of cores after different displacement processes are shown in Fig. 1, taking Core 2 as an example. The relaxation time $T_{2}$ represents the different pore radii, while the signal amplitude represents the oil saturation. Based on the Eqs. (1) and (2) and combined with the mercury intrusion data, a relationship between the $T_{2}$ distribution and the distribution of different pore radii was established. According to the

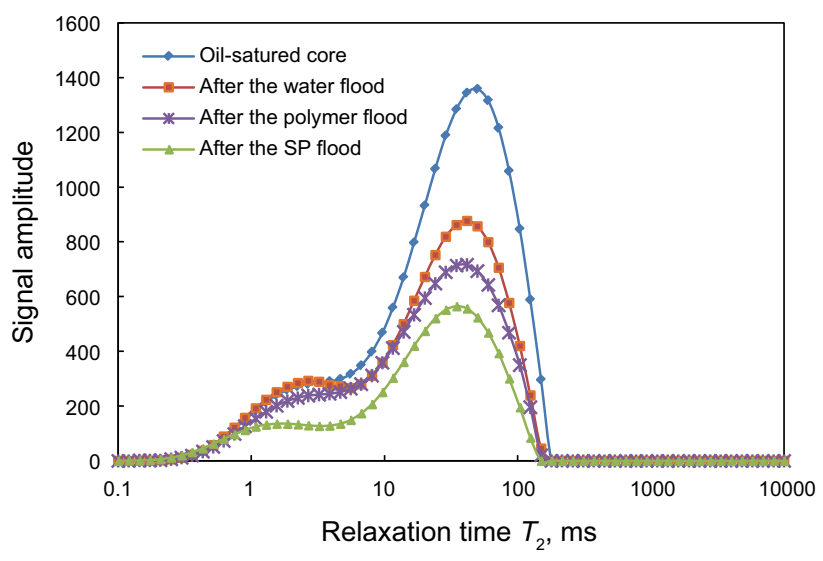

Fig. 1 NMR $T_{2}$ spectrums of Core 2 measured after different displacement processes 
analysis, the small pores (less than $2 \mu \mathrm{m}$ ) were defined as the pores with $T_{2}$ less than $10 \mathrm{~ms}$, the medium pores $(2-10 \mu \mathrm{m})$ were defined as the pores with $T_{2}$ between $10 \mathrm{~ms}$ and $50 \mathrm{~ms}$, and the large pores (more than $10 \mu \mathrm{m}$ ) were defined as the pores with $T_{2}$ longer than $50 \mathrm{~ms}$.

\section{Experimental method and procedures}

\subsection{Experimental materials and apparatus}

Oil samples used were a mixture of crude oil from West Dagang III area and kerosene. It had a viscosity of $17 \mathrm{mPa} \mathrm{s}$ at $53{ }^{\circ} \mathrm{C}$, similar to the crude oil at reservoir conditions. Brines were synthetic formation water prepared in the laboratory with a composition as listed in Table 1. Additional $\mathrm{Mn}^{2+}$ ions in the brines were the paramagnetic ions. Before use, brines were filtered by a $0.45 \mu \mathrm{m}^{2}$ filter membrane.

Partially hydrolyzed polyacrylamide (PHPA) had an average molecular weight of 25 million Daltons, a purity of over $88 \%$, and a degree of hydrolysis of $25 \%$. PHPA solutions of four concentrations were measured with a Brookfield DV II viscometer, and it was found that about $10 \%$ of viscosity was lost after adding $\mathrm{Mn}^{2+}$ ions in PHPA solutions. DWS-3 nonionic surfactant (a mixed petroleum sulfonate surfactant) used in this study had an effective content of $40 \%$. No apparent change of the interfacial tension (IFT) was observed after adding $\mathrm{Mn}^{2+}$ ions to SP solutions. Experimental temperature was $53{ }^{\circ} \mathrm{C}$ (reservoir temperature). All these solutions were filtered by a $0.75 \mu \mathrm{m}^{2}$ sand core funnel before use. Natural cores were sampled from the West Dagang III Oilfield and shaped into cylinders with a diameter of $2.5 \mathrm{~cm}$ and a length of 6-8 $\mathrm{cm}$. Some experimental parameters and displacement fluid characteristics are listed in Table 2.

A low-frequency NMR spectrometer, Reccore-04, developed by the Institute of Porous Fluid Mechanics at the Chinese Academy of Sciences was used to analyze the distribution of oil in cores after different displacement processes.

\subsection{Surfactant-polymer solutions}

Twelve different SP solutions were designed to investigate the effects of interfacial tension (IFT) reduction and mobility control on residual oil distribution. The viscosities of SP solutions were measured with a Brookfield DV II viscometer at a shear rate of $7.34 \mathrm{~s}^{-1}$. The IFTs of SP solutions were measured with a TX500 spinning drop interface tensiometer at 5000 revolutions per minute (RPM) and $53{ }^{\circ} \mathrm{C}$. The details of $12 \mathrm{SP}$ solutions are listed in Table 2.

\subsection{Experimental procedures}

(1) The core sample was evacuated for $2 \mathrm{~h}$ to remove air and then fully saturated with brines. The core permeability to brine was evaluated.

(2) The core sample was oil flooded to residual water saturation (no further water production at the core outlet). Initial oil saturation distribution in the core was measured with an NMR spectrometer. After aging for 30 days, the core was water flooded until no further oil was produced at the core outlet and then the oil saturation distribution was tested again with the NMR spectrometer.

(3) The core was flooded with 3 pore volume (PV) of PHPA solutions with concentrations ranging from 1000 to $2500 \mathrm{mg} / \mathrm{L}$ (polymer displacement) and retested with the NMR spectrometer.

(4) The core was flooded with 3 PV of the SP solution (SP displacement), followed by water flooding until no further oil was produced. A final NMR test was then performed.

In core displacement tests, the injection rate was kept at $0.1 \mathrm{~mL} / \mathrm{min}$ and the pressure during polymer displacement and SP displacement was controlled below 2.5 times of the water displacement pressure. A schematic of the core displacement system is shown in Fig. 2.

\section{Results and discussion}

\subsection{Experimental results}

Results of 12 core displacement tests are listed in Table 3. The overall oil recovery ranged from $52.6 \%$ to $69.2 \%$. Oil recovery after the water flood was approximately $38.6 \%$ $41.8 \%$, while an incremental oil recovery of $6.5 \%-9.8 \%$ over the water flood was achieved by the polymer flood and

Table 1 Ion composition of brine

\begin{tabular}{|c|c|c|c|c|c|c|c|c|c|c|}
\hline Ion & $\mathrm{K}^{+}+\mathrm{Na}^{+}$ & $\mathrm{Mg}^{2+}$ & $\mathrm{Ca}^{2+}$ & $\mathrm{HCO}^{3-}$ & $\mathrm{CO}_{3}^{2-}$ & $\mathrm{Cl}^{-}$ & Total salinity & $\mathrm{Mn}^{2+}$ & $\mathrm{Cl}^{-}$ & Total salinity with $\mathrm{MnCl}_{2}$ \\
\hline Content, $\mathrm{mg} / \mathrm{L}$ & 2043 & 36 & 39 & 3126 & 135 & 1347 & 6726 & 1000 & 2000 & 9726 \\
\hline
\end{tabular}


Table 2 Basic parameters of core samples and characteristics of SP displacement fluids

\begin{tabular}{|c|c|c|c|c|c|c|c|}
\hline $\begin{array}{l}\text { Core } \\
\text { number }\end{array}$ & Porosity, \% & $\begin{array}{l}\text { Gas permeability, } \\
10^{-3} \mu \mathrm{m}^{2}\end{array}$ & Oil saturation, $\%$ & $\begin{array}{l}\text { Polymer } \\
\text { concentration, } \\
\mathrm{mg} / \mathrm{L}\end{array}$ & $\begin{array}{l}\text { Surfactant } \\
\text { concentration, \% }\end{array}$ & $\begin{array}{l}\text { Viscosity of the } \\
\text { SP solution, mPa s }\end{array}$ & IFT, $\mathrm{mN} / \mathrm{m}$ \\
\hline 1 & 29.6 & 636 & 73.8 & 1000 & 0.15 & 11.73 & $1.49 \times 10^{-2}$ \\
\hline 2 & 30.0 & 629 & 72.8 & 1500 & 0.15 & 39.67 & $2.03 \times 10^{-2}$ \\
\hline 3 & 29.6 & 638 & 72.9 & 2000 & 0.15 & 71.23 & $3.97 \times 10^{-2}$ \\
\hline 4 & 28.8 & 624 & 72.5 & 2500 & 0.15 & 117.33 & $5.56 \times 10^{-2}$ \\
\hline 5 & 29.2 & 635 & 72.6 & 1000 & 0.25 & 10.67 & $5.28 \times 10^{-3}$ \\
\hline 6 & 29.4 & 632 & 72.8 & 1500 & 0.25 & 38.40 & $7.47 \times 10^{-3}$ \\
\hline 7 & 29.9 & 626 & 73.7 & 2000 & 0.25 & 70.40 & $8.92 \times 10^{-3}$ \\
\hline 8 & 30.0 & 630 & 73.0 & 2500 & 0.25 & 115.20 & $1.53 \times 10^{-2}$ \\
\hline 9 & 29.1 & 628 & 73.9 & 1000 & 0.30 & 10.67 & $3.04 \times 10^{-3}$ \\
\hline 10 & 29.6 & 637 & 73.9 & 1500 & 0.30 & 38.40 & $5.53 \times 10^{-3}$ \\
\hline 11 & 30.0 & 636 & 73.9 & 2000 & 0.30 & 70.40 & $7.80 \times 10^{-3}$ \\
\hline 12 & 29.0 & 627 & 72.6 & 2500 & 0.30 & 115.20 & $1.08 \times 10^{-2}$ \\
\hline
\end{tabular}

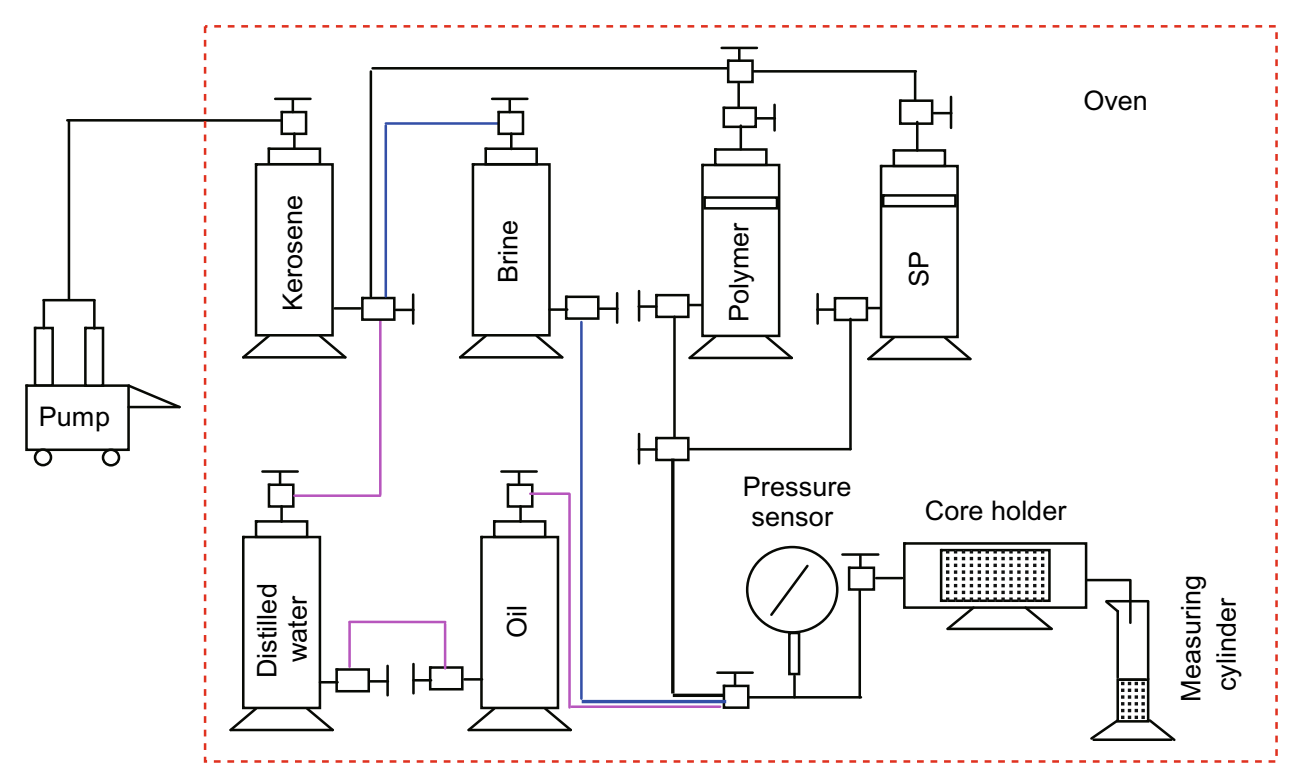

Fig. 2 Schematic illustration of the core displacement system

$4.5 \%-21.5 \%$ over the polymer flood achieved by the subsequent SP flood. As shown in Table 3, with a constant surfactant concentration in the case of SP flood, the incremental oil recovery increased when the polymer concentration changed from $1000 \mathrm{mg} / \mathrm{L}$ to $2500 \mathrm{mg} / \mathrm{L}$. The ultimate incremental oil recovery had a positive correlation with the polymer concentration.

Xia et al. (2006) proposed that a reduction in residual oil saturation by polymer flooding might be owing to the viscoelasticity of a polymer solution. When the polymer viscoelasticity increased with an increase in its concentration, the interaction between the polymer solution and the residual oil increased, and more residual oil would be displaced from reservoir pores. However, after the polymer concentration exceeded a limit, the inaccessible pore volume would increase and the incremental oil recovery owing to additional increase in the polymer concentration would be insignificant (Guo et al. 2014). The sweep efficiency by the polymer flood may even decrease due to incompatibility between the polymer molecules and the pore size.

Figure 3 indicates that for a constant polymer concentration, an incremental oil recovery of $7.5 \%-10.5 \%$ was achieved after the SP flood when the surfactant concentration changed from $0.15 \%$ to $0.25 \%$ (curves in Fig. 3 are steep when the surfactant concentration is low). This 
Table 3 Data on 12 core displacement tests

\begin{tabular}{lllll}
\hline $\begin{array}{l}\text { Core } \\
\text { number }\end{array}$ & $\begin{array}{l}\text { Oil recovery by } \\
\text { the water flood, } \%\end{array}$ & $\begin{array}{l}\text { Incremental oil recovery } \\
\text { by the polymer flood, } \%\end{array}$ & $\begin{array}{l}\text { Incremental oil recovery } \\
\text { by the SP flood, } \%\end{array}$ & $\begin{array}{l}\text { Overall oil } \\
\text { recovery, } \%\end{array}$ \\
\hline 1 & 40.4 & 7.7 & 4.5 & 52.6 \\
2 & 39.8 & 8.0 & 5.8 & 53.6 \\
3 & 41.0 & 6.5 & 10.1 & 57.6 \\
4 & 41.8 & 7.0 & 10.4 & 59.2 \\
5 & 39.1 & 8.1 & 12.0 & 59.1 \\
6 & 40.6 & 9.1 & 14.3 & 64.0 \\
7 & 39.2 & 8.0 & 18.9 & 66.0 \\
8 & 39.4 & 8.1 & 20.9 & 68.4 \\
9 & 41.5 & 8.8 & 13.0 & 63.2 \\
10 & 39.1 & 9.8 & 15.7 & 64.6 \\
11 & 41.7 & 6.8 & 19.2 & 67.6 \\
\hline
\end{tabular}

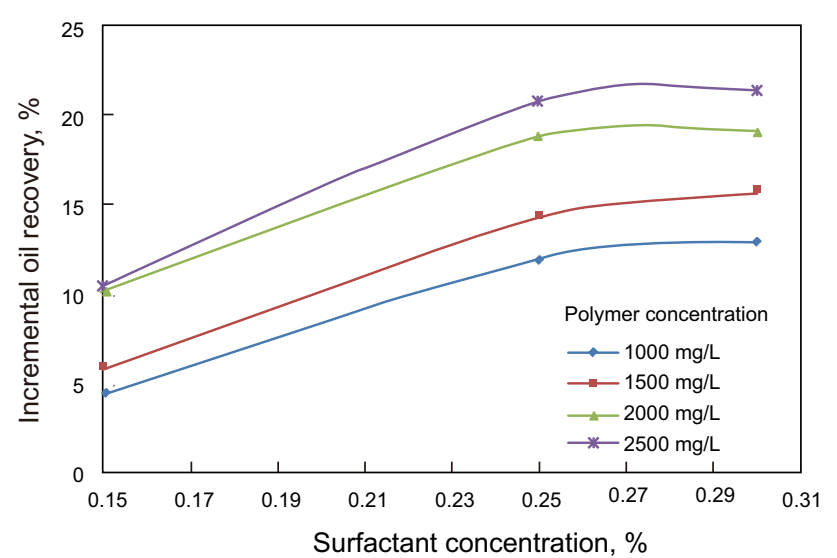

Fig. 3 Incremental oil recovery as a function of surfactant concentration for SP displacement processes of different polymer concentrations

increment was due to an increase in the surfactant concentration. However, when the surfactant concentration changed from $0.25 \%$ to $0.30 \%$, the incremental oil recovery increased slowly from $0.3 \%$ to $1.4 \%$ (curves in Fig. 3 are relatively flat when the surfactant concentration is high).

From Tables 2 and 3, we concluded that the residual oil was obviously removed by the displacement solution when the IFT was lowered to $10^{-3} \mathrm{mN} / \mathrm{m}$. The overall oil recovery had a positive correlation with the surfactant concentration. The addition of surfactant would reduce the interfacial tension between crude oil and water, increase the capillary number, and thus decrease the adhesive force between oil and rock surfaces (Shi et al. 2012). On the other hand, when the injected surfactant solution contacted crude oil, an emulsion was formed, in which oil was the dispersed phase. Oil was removed, as the emulsion was displaced through the formation, rather than tending to adhere to pore surfaces, resulting in an incremental oil recovery. In summary, the incremental oil recovery was attributed to the synergism between polymer and surfactant (Kendall and Martin 2007; Lai et al. 2014).

\subsection{Quantitative calculations of oil recovery from different pores}

With the correlation between pore throat sizes and NMR $T_{2}$ time distribution ( $\mathrm{Li}$ et al. 2008), recovery factors by the water flood, polymer flood, and the SP flood from pores of different sizes were calculated and are listed in Table 4. The recovery factor is defined as the ratio of the volume of oil displaced from pores of a specific size to the total volume of oil trapped in the pores of the same size.

Table 4 shows that the oil was first mobilized from pores with relatively large pore sizes by the water flood, rather than that trapped in small or medium pores. During polymer flooding, the mobility of the displacing phase was controlled by the polymer. The residual oil in small pores could be "kicked off" due to the pressure increase. However, with an increase in the polymer concentration, the inaccessible pore volume increased and the polymer could not enter into small pores. Consequently, when the polymer concentration increased, the oil recovery from small pores reduced. During SP flooding, the surfactant was used to reduce IFT and the polymer could control mobility of the displacing fluid. As a result, both the displacement efficiency and the sweep efficiency were improved for naturally heterogeneous cores.

Figure 4 shows that the recovery factor from small pores after the SP flood decreased with an increase in the 
Table 4 Recovery factors of oil from pores of different sizes after the water flood, polymer flood, and the SP flood, respectively

\begin{tabular}{|c|c|c|c|c|c|c|c|c|c|c|c|}
\hline \multirow[t]{2}{*}{$\begin{array}{l}\text { Core } \\
\text { number }\end{array}$} & \multirow{2}{*}{$\begin{array}{l}\text { Polymer } \\
\text { concentration, } \\
\mathrm{mg} / \mathrm{L}\end{array}$} & \multirow{2}{*}{$\begin{array}{l}\text { Surfactant } \\
\text { concentration, } \\
\%\end{array}$} & \multicolumn{3}{|c|}{$\begin{array}{l}\text { Recovery factor by the water } \\
\text { flood, } \%\end{array}$} & \multicolumn{3}{|c|}{$\begin{array}{l}\text { Recovery factor by the polymer } \\
\text { flood, } \%\end{array}$} & \multicolumn{3}{|c|}{$\begin{array}{l}\text { Recovery factor by the SP } \\
\text { flood, } \%\end{array}$} \\
\hline & & & $\begin{array}{l}\text { Small } \\
\text { pores }\end{array}$ & $\begin{array}{l}\text { Medium } \\
\text { pores }\end{array}$ & $\begin{array}{l}\text { Large } \\
\text { pores }\end{array}$ & $\begin{array}{l}\text { Small } \\
\text { pores }\end{array}$ & $\begin{array}{l}\text { Medium } \\
\text { pores }\end{array}$ & $\begin{array}{l}\text { Large } \\
\text { pores }\end{array}$ & $\begin{array}{l}\text { Small } \\
\text { pores }\end{array}$ & $\begin{array}{l}\text { Medium } \\
\text { pores }\end{array}$ & $\begin{array}{l}\text { Large } \\
\text { pores }\end{array}$ \\
\hline 1 & 1000 & 0.15 & 8.4 & 41.5 & 59.4 & 21.0 & 5.8 & 5.1 & 16.7 & 3.1 & 4.4 \\
\hline 2 & 1500 & & 8.1 & 40.8 & 59.8 & 20.0 & 6.3 & 6.1 & 15.7 & 4.8 & 5.6 \\
\hline 3 & 2000 & & 8.3 & 41.1 & 60.6 & 14.1 & 6.5 & 9.0 & 13.8 & 9.9 & 10.1 \\
\hline 4 & 2500 & & 8.5 & 41.5 & 61.1 & 12.3 & 7.4 & 9.6 & 11.5 & 10.7 & 12.2 \\
\hline 5 & 1000 & 0.25 & 8.0 & 40.9 & 60.2 & 20.5 & 6.0 & 5.4 & 32.9 & 9.7 & 10.3 \\
\hline 6 & 1500 & & 8.6 & 42.1 & 61.2 & 20.1 & 6.8 & 6.2 & 30.5 & 12.0 & 14.1 \\
\hline 7 & 2000 & & 8.3 & 40.7 & 60.2 & 13.2 & 7.1 & 8.9 & 24.7 & 18.8 & 17.1 \\
\hline 8 & 2500 & & 8.2 & 40.8 & 61.2 & 12.0 & 7.9 & 9.9 & 19.1 & 22.0 & 18.2 \\
\hline 9 & 1000 & 0.30 & 8.1 & 41.1 & 62.0 & 21.0 & 6.2 & 5.4 & 33.8 & 11.2 & 11.8 \\
\hline 10 & 1500 & & 8.2 & 40.9 & 60.2 & 18.2 & 6.9 & 6.0 & 30.6 & 12.7 & 14.6 \\
\hline 11 & 2000 & & 8.1 & 42.0 & 62.8 & 13.9 & 7.2 & 8.4 & 27.2 & 19.9 & 17.9 \\
\hline 12 & 2500 & & 7.9 & 41.8 & 60.8 & 11.9 & 8.0 & 9.8 & 23.5 & 22.9 & 18.5 \\
\hline
\end{tabular}

polymer concentration when the surfactant concentration was fixed. This phenomenon was due to the incompatibility between the polymer molecular size and the pore size (Lu et al. 2009; Li et al. 2014; Yin et al. 2014). However, when the polymer concentration was fixed in the SP flood, the IFT reduced and the capillary number increased with an increase in the surfactant concentration, so the residual oil saturation reduced and the recovery factor from small pores enhanced.

Figure 5 shows that the recovery factor from medium pores after the SP flood increased significantly with an increase in the polymer concentration when the surfactant concentration was fixed. This improvement of oil recovery was due to the increased viscosity or viscoelasticity of the SP solution.

Figure 6 shows that the recovery factor from large pores increased gradually with an increase in the polymer concentration when the surfactant concentration was fixed

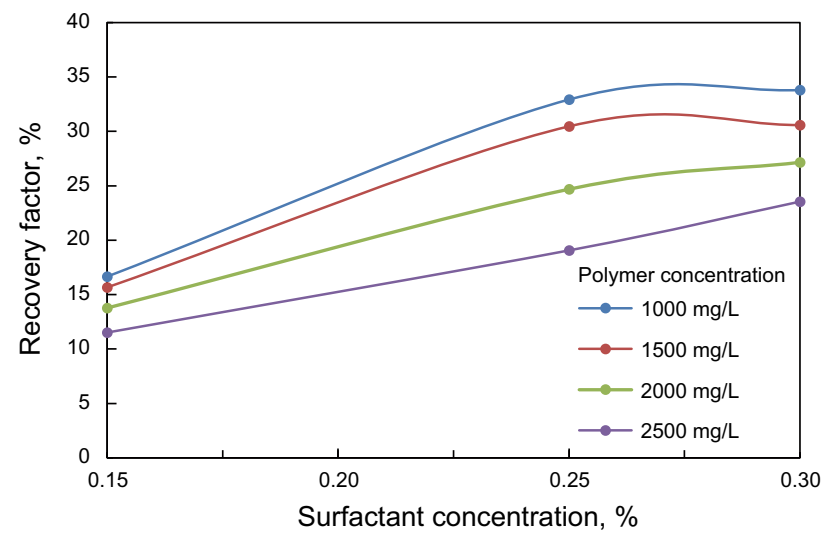

Fig. 4 Recovery factor of oil from small pores after SP floods

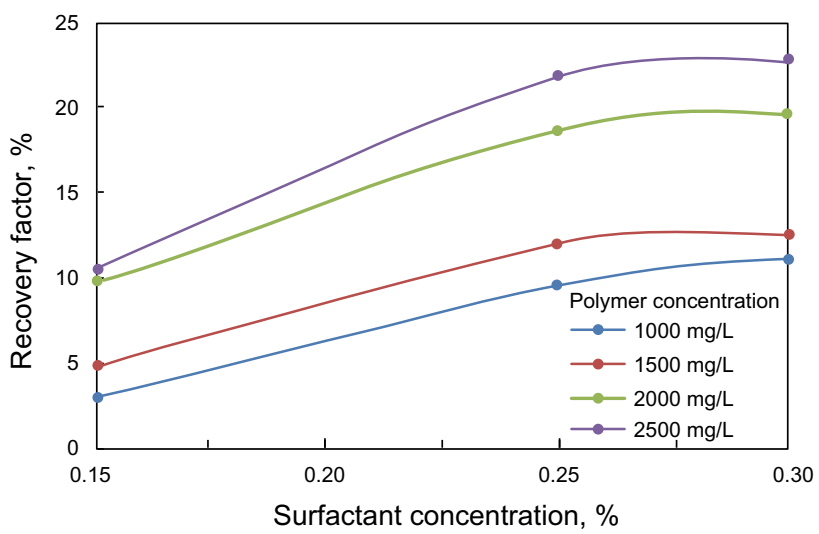

Fig. 5 Recovery factor of oil from medium pores after SP floods

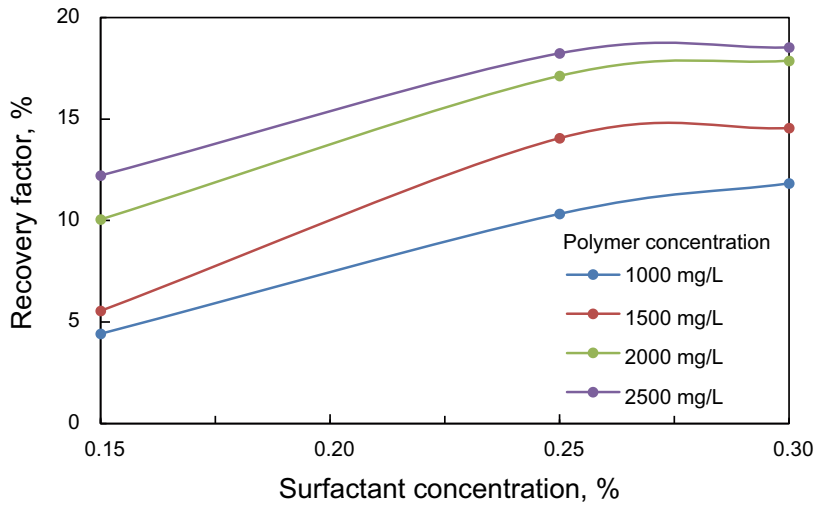

Fig. 6 Recovery factor of oil from large pores after SP floods

during SP flooding. However, the increasing trend became less steep after the polymer concentration increased to $2000 \mathrm{mg} / \mathrm{L}$. 
We concluded from Figs. 5 and 6 that if the polymer concentration was fixed the oil recovery from medium or large pores was enhanced significantly when the surfactant concentration increased. After the surfactant concentration increased to $0.25 \%$, the increasing trend became less steep.

\subsection{Contribution of different pores to oil recovery during SP flooding}

As shown in Table 5, with the surfactant concentration fixed at $0.15 \%$, when the polymer concentration increased the large pore contribution did not change significantly, and the medium pore contribution increased while the small pore contribution decreased. The reason was that there was little residual oil in large pores. Therefore, if the IFT could not be reduced, the residual oil would be very difficult to displace. In this case, the flow resistance increased as polymer molecules entered large pores, thus the SP solution was diverted into medium pores, which led to an increase in the sweep efficiency in medium pores (Dang et al. 2011).

When the surfactant concentration was fixed at $0.25 \%$ or $0.30 \%$, the contribution from medium and large pores increased with an increase in the polymer concentration, especially medium pores, but the small pore contribution decreased. The reason was that the hydrodynamic size of the polymer was larger than the size of small pores. Therefore, polymer molecules could not penetrate into small pores (Pye 1964; Gogarty 1967; Gogarty et al. 1970; $\mathrm{Lu}$ and Gao 1996). The synergy effect of surfactant and polymer also influenced IFT and emulsification. The flow resistance was reduced due to the reduction in IFT achieved by the SP system. On the other hand, the

Table 5 Recovery contribution of different pores during SP flooding

\begin{tabular}{llllll}
\hline $\begin{array}{l}\text { Core } \\
\text { number }\end{array}$ & $\begin{array}{l}\text { Polymer } \\
\text { concentration, } \\
\text { mg/L }\end{array}$ & $\begin{array}{l}\text { Surfactant } \\
\text { concentration, }\end{array}$ & $\begin{array}{l}\text { Contribution to oil } \\
\text { recovery in the SP } \\
\text { flood, } \%\end{array}$ \\
\cline { 3 - 6 } & & & $\begin{array}{l}\text { Small } \\
\text { pores }\end{array}$ & $\begin{array}{l}\text { Medium } \\
\text { pores }\end{array}$ & $\begin{array}{l}\text { Large } \\
\text { pores }\end{array}$ \\
\hline 1 & 1000 & 0.15 & 58.4 & 18.8 & 24.9 \\
2 & 1500 & & 53.3 & 23.0 & 23.6 \\
3 & 2000 & & 36.8 & 37.8 & 25.4 \\
4 & 2500 & & 26.7 & 49.6 & 23.7 \\
5 & 1000 & 0.25 & 36.3 & 39.6 & 24.1 \\
6 & 1500 & & 32.4 & 40.7 & 26.9 \\
7 & 2000 & & 27.0 & 42.8 & 30.2 \\
8 & 2500 & & 19.7 & 49.6 & 30.6 \\
9 & 1000 & 0.30 & 35.9 & 40.3 & 23.7 \\
10 & 1500 & & 34.8 & 42.8 & 29.9 \\
11 & 2000 & & 29.5 & 43.2 & 29.4 \\
12 & 2500 & & 20.6 & 49.6 & 29.9 \\
\hline
\end{tabular}

Table 6 Distribution of residual oil in different pores after the SP flood

\begin{tabular}{lllllr}
\hline $\begin{array}{l}\text { Core } \\
\text { number }\end{array}$ & $\begin{array}{l}\text { Polymer } \\
\text { concentration, } \\
\text { mg/L }\end{array}$ & $\begin{array}{l}\text { Surfactant } \\
\text { concentration, } \\
\%\end{array}$ & & \multicolumn{3}{l}{$\begin{array}{l}\text { Residual oil in different } \\
\text { pores, } \%^{\mathrm{a}}\end{array}$} \\
\cline { 4 - 6 } & & 0.15 & $\begin{array}{l}\text { Small } \\
\text { pores }\end{array}$ & $\begin{array}{l}\text { Medium } \\
\text { pores }\end{array}$ & $\begin{array}{l}\text { Large } \\
\text { pores }\end{array}$ \\
\hline 1 & 1000 & & 12.8 & 26.0 & 9.3 \\
2 & 1500 & & 12.5 & 24.8 & 9.2 \\
3 & 2000 & & 12.9 & 21.7 & 7.9 \\
4 & 2500 & 0.25 & 13.8 & 19.5 & 7.5 \\
5 & 1000 & & 10.3 & 19.8 & 10.5 \\
6 & 1500 & & 10.7 & 18.3 & 7.1 \\
7 & 2000 & & 11.7 & 17.4 & 4.8 \\
8 & 2500 & 0.30 & 13.4 & 14.9 & 3.2 \\
9 & 1000 & & 10.9 & 18.8 & 7.0 \\
10 & 1500 & & 11.3 & 16.8 & 4.2 \\
11 & 2000 & & 13.0 & 14.7 & 3.1 \\
12 & 2500 & & & 18.2 & 6.5 \\
\hline
\end{tabular}

${ }^{a}$ The ratio of the volume of residual oil in the specific pores after the SP flood to the total volume of oil in all pores before the water flood

stable emulsion slug increased the pressure gradient in the pores. Some residual oil was carried away with the emulsion. In summary, the medium pore contribution after the SP flood was the highest, ranging from $40 \%$ to $49 \%$. Small and large pore contributions were relatively lower.

\subsection{Residual oil in pores}

As shown in Table 6, most of residual oil was found in medium pores, followed by small pores and large pores. When the polymer concentration was fixed, the recovery from all pores of different sizes increased significantly. When the surfactant concentration was fixed, residual oil in the large and medium pores was reduced with increasing polymer concentration. Meanwhile, the residual oil in small pores increased slightly. Therefore, the IFT should be reduced to ultralow $\left(10^{-3} \mathrm{mN} / \mathrm{m}\right)$ level to improve displacement efficiency in small pores.

\section{Conclusions}

(1) For an SP flood with a fixed surfactant concentration, when the polymer concentration increased, the oil recovery from small pores was reduced due to the incompatibility between the polymer molecule size and the small pore size. Meanwhile, the oil recovery from the medium and large pores increased due to increased viscosity or viscoelasticity of the SP solution. 
(2) For an SP flood with a fixed polymer concentration, when the surfactant concentration increased, the oil recovery from all pore sizes increased significantly. When the surfactant concentration reached $0.25 \%$, the incremental oil recovery became negligible. After the IFT was reduced to an ultralow level of about $10^{-3} \mathrm{mN} /$ $\mathrm{m}$, the oil recovery could not be improved significantly by increasing the surfactant concentration.

(3) After the polymer and surfactant concentrations increased to critical values, additional increases in their concentrations led to a slight improvement in the overall oil recovery. For economic reasons, an SP system of $2000 \mathrm{mg} / \mathrm{L}$ polymer and $0.25 \%$ surfactant was recommended.

(4) Contribution from medium pores was the highest among all the three groups of pores, accounting for about $40 \%-49 \%$, during SP flooding. Although the SP system mainly displaced the residual oil in medium pores, its effect on the residual oil in small and large pores cannot be neglected. After the SP flood, the residual oil was mainly trapped in small and medium pores, so the oil in small and medium pores was the main target for enhanced oil recovery after the SP flood.

Acknowledgments The authors would like to thank Scientific Research Foundation of China University of Petroleum, Beijing (No. 2462013YJRC033) and (No. 01JB0177) for funding this research.

Open Access This article is distributed under the terms of the Creative Commons Attribution 4.0 International License (http://crea tivecommons.org/licenses/by/4.0/), which permits unrestricted use, distribution, and reproduction in any medium, provided you give appropriate credit to the original author(s) and the source, provide a link to the Creative Commons license, and indicate if changes were made.

\section{References}

Ausbrooks R, Hurley NF, May A, et al. Pore-size distribution in vuggy carbonates from core images, NMR, and capillary pressure. In: SPE annual technical conference and exhibition, 3-6 October, Houston, Texas; 1999. doi:10.2118/56506-MS.

Cowan B. Nuclear magnetic resonance and relaxation. New York: Cambridge University Press; 1997.

Dang CTQ, Chen ZJ, Nguyen NTB, et al. Development of isotherm polymer/surfactant adsorption models in chemical flooding. In: SPE Asia Pacific oil and gas conference and exhibition, 20-2 September, Jakarta, Indonesia; 2011. doi:10.2118/147872-MS.

de Argandona VGR, Rey AR, Celorio C, et al. Characterization by computed X-ray tomography of the evolution of the pore structure of a dolomite rock during freeze-thaw cyclic tests. Phys Chem Earth Part A. 1999;24(7):633-7. doi:10.1016/S14641895(99)00092-7.

Gleeson JW, Woessner DE, Jordan CF Jr. NMR imaging of pore structures in limestones. SPE Formation Evalu. 1993;8(2):123-7. doi:10.2118/20493-PA.
Gogarty WB. Mobility control with polymer solutions. SPE J. 1967;7(2):161-73. doi:10.2118/1566B-PA.

Gogarty WB, Meabon HP, Milton HW Jr. Mobility control design for miscible-type waterfloods using micellar solutions. J Pet Technol. 1970;22(2):141-7. doi:10.2118/1847-E-PA.

Gong G, Sun B, Liu M, et al. NMR relaxation of the fluid in rock porous media. Chin J Magn Reson. 2006;23(3):380-94 (in Chinese).

Guo A, Geng Y, Zhao L, et al. Preparation of cationic polyacrylamide microsphere emulsion and its performance for permeability reduction. Pet Sci. 2014;11(3):408-16. doi:10.1007/s12182-0140355-0.

Guo $\mathrm{G}, \mathrm{Gu}$ C. Oil saturation in rock cuttings measured by nuclear magnetic resonance. Chin J Magn Reson. 2005;22(1):67-72 (in Chinese).

Kendall TA, Martin ST. Water-induced reconstruction that affects mobile ions on the surface of calcite. J Phys Chem A. 2007;111(3):505-14. doi:10.1021/jp0647129.

Kleinberg R, Vinegar HJ. NMR properties of reservoir fluids. Log Anal. 1996;37(6):20-32.

Lai N, Zhang X, Ye Z, et al. Laboratory study of an anti-temperature and salt-resistance surfactant-polymer binary combinational flooding as EOR chemical. J Appl Polym Sci. 2014. doi:10. 1002/app.39984.

Lake LW. Enhanced oil recovery. Englewood Cliffs: Prentice Hall; 1989.

Li H, Liu Q, Wen C, et al. Residual oil distribution and potential tapping study. Spec Oil Gas Reserv. 2006;13(3):8-11 (in Chinese).

Li H, Zhu J, Guo H. Methods for calculating pore radius distribution in rock from NMR $T_{2}$ spectra. Chin $\mathrm{J}$ Magn Reson. 2008;25(1):67-72 (in Chinese).

Li Y, Gao J, Yin D, et al. Study of the matching relationship between polymer hydrodynamic characteristic size and pore throat radius of target blocks based on the micro porous membrane filtration method. J Chem. 2014. doi:10.1155/2014/569126.

Liu H. Study of meso-structure and damage mechanical characteristics of frozen rock based on CT image processing. Xi' an: Xi' an University of Science and Technology; 2013 (in Chinese).

Liu Y, Liu Y, Sui X. Characteristics of pore structure of transitional zone of Saertu central area in Daqing Oilfield. J Daqing Pet Inst. 2004;28(1):109-11 (in Chinese).

Lu G, Zhang X, Shao C, et al. Molecular dynamics simulation of adsorption of an oil-water-surfactant mixture on calcite surface. Pet Sci. 2009;6(1):76-81. doi:10.1007/s12182-009-0014-z.

$\mathrm{Lu} \mathrm{X,} \mathrm{Gao} \mathrm{Z.} \mathrm{Pore} \mathrm{throat} \mathrm{radius} \mathrm{to} \mathrm{coil} \mathrm{gyration} \mathrm{radius} \mathrm{ratio} \mathrm{as}$ characteristic of adaptively of polymer molecular mass to core permeability. Oilfield Chem. 1996;13(1):72-5 (in Chinese).

Pye DJ. Improved secondary recovery by control of the water mobility. J Pet Technol. 1964;16(8):911-6. doi:10.2118/845-PA.

Shi L, Chen L, Ye Z, et al. Effect of polymer solution structure on displacement efficiency. Pet Sci. 2012;9(2):230-5. doi:10.1007/ s12182-012-0203-z.

Sorbie KS. Polymer-improved oil recovery. Baca Raton: CRC Press; 1991.

Vinegar HJ. X-ray CT and NMR imaging of rocks. J Pet Technol. 1986;38(3):257-9. doi:10.2118/15277-PA.

Wang W, Guo H, Ye C. Experimental studies of NMR properties of continental sedimentary rocks. Chin J Magn Reson. 2001;18(2):113-21 (in Chinese).

Wang Y, Zhao F, Bai B, et al. Optimized surfactant IFT and polymer viscosity for surfactant-polymer flooding in heterogeneous formations. In: SPE improved oil recovery symposium, 24-8 April, Tulsa, Oklahoma; 2010. doi:10.2118/127391-MS.

Williams JLA, Taylor DG, Maddinelli G, et al. Visualisation of fluid displacement in rock cores by NMR imaging. Magn Reson 
Imaging. 1991;9(5):767-73. doi:10.1016/0730-725X(91)90374$\mathrm{U}$.

Xia H, Wang D, Wang G, et al. Elastic behavior of polymer solution to residual oil at dead-ends. Acta Petrolei Sinica. 2006;27(02):72-6 (in Chinese).

Xie R, Xiao L. Dispersion properties of NMR relaxation for crude oil. Pet Sci. 2007;4(2):35-8. doi:10.1007/BF03187439.

Yin D, Li Y, Chen B, et al. Study of compatibility of polymer hydrodynamic size and pore throat size for Honggang reservoir. Int J Polym Sci. 2014. doi:10.1155/2014/729426.
Zao M, Guo Z, Qing H, et al. Identification of thin rock cast section and application of microscopic image analysis technology. WestChina Explor Eng. 2009;3:66-7 (in Chinese).

Zhao Y, Song Y, Liu Y, et al. Visualization of $\mathrm{CO}_{2}$ and oil immiscible and miscible flow processes in porous media using NMR microimaging. Pet Sci. 2011;8(2):183-93. doi:10.1007/s12182-0110133-1. 